\title{
To Approach or to Avoid: The Role of Ambivalent Motivation in Attentional Biases to Threat and Spider Fear
}

\author{
Mengran $\mathrm{Xu}^{1}{ }^{1} \cdot$ Katelyn Rowe $^{1} \cdot$ Christine Purdon $^{1}$
}

Accepted: 7 December 2020

(C) The Author(s), under exclusive licence to Springer Science+Business Media, LLC part of Springer Nature 2021

\begin{abstract}
Background People with anxiety difficulties show different patterns in their deployment of attention to threat compared to people without anxiety difficulties. These attentional biases are assumed to play a critical role in the development and persistence of anxiety. However, little is known about factors that influence attentional biases to threat. An emerging body of evidence suggests that visual attention to threat varies across the time course according to one's motivation to approach vs. avoid threat.

Methods In order to better understand the relationship between motivation, attentional biases to threat, and anxiety, we had participants high in spider fear complete a sustained-attention task in full view of a live tarantula while their eye movements were tracked.

Results Participants who were ambivalent about whether to look at the spider or to avoid looking exhibited a unique pattern of visual attention to the spider, and reported higher spider fear and more negative affect than did other participants at the end of the study.

Conclusions Our findings suggest that anxiety persistence may have more to do with goal prioritization than innate attentional biases. Future studies of attentional biases to threat should take motivation into account and study attention across the time course. Ambivalent motivation to threat should also be targeted in exposure therapy.
\end{abstract}

Keywords Attentional bias to threat $\cdot$ Approach-avoidance conflict $\cdot$ Ambivalent motivation $\cdot$ Spider fear $\cdot$ Spider anxiety

\section{Introduction}

It is generally accepted that anxiety influences attentional deployment to threat cues (see Bar-Haim et al. 2007; Cisler and Koster 2010; Mathews and Mackintosh 1998; Mogg and Bradley 1998; Williams et al. 1988). People with high trait anxiety exhibit three types of attentional biases. The first is rapid detection of threat relative to neutral cues, and is referred to as "facilitated attention" (e.g., Yiend and Mathews 2001). The second is sustained attention to threat and longer latency to shift attention away from threat, which are referred to collectively as "difficulty disengaging from threat" (e.g., Fox et al. 2001). The third type of bias is preferential allocation of attention towards locations opposite the

Mengran Xu

mengran.xu@uwaterloo.ca

1 Department of Psychology, University of Waterloo, 200 University Avenue West, Waterloo, ON N2L 3G1, Canada location of the threat cue, referred to as "attentional avoidance" (e.g., Koster et al. 2006).

These attentional biases may be important factors in the development and persistence of anxiety problems. Attentional biases to threat have been observed in almost all anxiety and related disorders, including social anxiety disorder (Amir et al. 2003), obsessive-compulsive disorder (Cisler and Olatunji 2010), generalized anxiety disorder (Mogg and Bradley 2005; Rinck et al. 2003), panic disorder (Buckley et al. 2002), post-traumatic stress disorder (Bryant and Harvey 1995), and spider phobia (Rinck et al. 2005). Moreover, results from a meta-analysis of 172 studies (Bar-Haim et al. 2007) confirmed that there is a robust link between attentional biases to threat and anxiety, with an effect size of $d=0.45$.

Decades of research has established that attentional biases to threat follow a vigilant-avoidant pattern (Mogg and Bradley 1998), with facilitated attention to threat occurring at an early, automatic stage of processing and avoidance of threat occurring at a later, strategic stage 
of processing (see Derryberry and Reed 2002; Mogg et al. 2004). More importantly, vigilance and avoidance combined result in repeated brief, insufficient exposures, through which anxiety is maintained (Rachman 2004). However, little is known about factors that account for this drastic change in direction for attentional biases to threat. Cisler and Koster (2010) argued that top-down processes, such as motivation and goals, may play an important role in modulating the initial attentional deployment to threat. According to Cisler and Koster (2010), attentional biases to threat may reflect "purposeful attempts to detect and cope with disorder-relevant sources of threat in the environment" (p. 211). For example, individuals who are motivated to cope with negative emotions induced by threat, may override their initial, automatic bias towards threat and deploy their attention away from threat later in the time course.

Indeed, there is a growing body of evidence showing that motivation does influence attentional processing of threat at a later stage of processing. Richeson and Trawalter (2008) found that participants who were highly motivated to respond to pictures without a racial bias showed facilitated attention to pictures of non-white people presented at stimulus durations of $30 \mathrm{~ms}$ and avoidance of non-white faces at stimulus durations of $450 \mathrm{~ms}$. Johnson (2009) found that participants instructed to pay attention to happy faces and to avoid angry faces showed facilitated attention towards happy faces and avoidance of angry faces at stimulus durations of 1250 ms. Dunning and Hajcak (2009) found that participants instructed to pay attention to non-arousing aspects of unpleasant pictures displayed decreased late positive potential, which indicates reduced facilitated attention.

There are two fundamental systems of motivation, namely approach and avoidance motivation (see Elliot and Thrash 2002; Gray and McNaughton 2000). However, to conceptualize anxiety as a dominance of one motivation over another may be oversimplifying. When faced with a threat in everyday life, people may have conflicting goals; on the one hand, they may think it is important to attend to the threat to keep themselves safe, but on the other hand doing so might detract from their current tasks or cause distress. The extent to which they attend to threat may have more to do with their situational goals than the emotional valence of the presenting stimulus. For example, people high in spider fear may be motivated to attend to spider stimuli, as they have been found to detect pictures of spiders more rapidly than neutral pictures (Ohman et al. 2001) and take longer to switch from spider cues to neutral cues (Paulitzki et al. 2008; Wilson et al. 2015). At the same time, people high in spider fear may also be motivated to avoid paying attention to spider stimuli, as they have been found to spend less time looking at spider images than neutral images (Hermans et al. 1999; Rinck and Becker 2006).
However, the above-mentioned studies were not without caveats. As Cisler and Koster (2010) pointed out, many of the paradigms used to study attentional deployment to threat assess attention at varying stimulus duration presentations (e.g., ranging from 17 to $500 \mathrm{~ms}$ ) as opposed to examining attention across time. Hence, it would be difficult to observe the influence of top-down process (such as motivation) on attention. Secondly, it should be noted that almost all previous studies examined spider-fearful individuals' attentional deployment to pictures of spiders instead of real spiders (e.g., Mogg and Bradley 2006; Vrijsen et al. 2009), thus limiting the ecological validity of their results.

In addition, these quite different biases could reflect not only the point in time at which the stimuli were presented (i.e., early vs. later stages of processing), but also goal conflict (i.e., approach vs. avoidance motivation). To examine the role of goal conflict in spider anxiety, Pittig et al. (2014) presented spider-fearful individuals with a gambling task that involved choosing cards from multiple decks which either had pictures of spiders on them and yielded greater gains, or featured pictures of butterflies and yielded greater losses. Participants showed initial avoidance of spider pictures and, despite some improvements over time, generally failed to learn to use the advantageous deck, in this case sacrificing reward in the service of anxiety reduction. When people have difficulty deciding which of the two conflicting goals to pursue, greater distress may result. Healey et al. (2019) had participants list and rate the importance of reasons for approaching and for avoiding spiders. Participants completed a self-directed exposure task and reported their spider-related distress two weeks following the exposure. Higher goal conflict was associated with higher distress at both baseline and follow-up.

With a similar research question in mind, Nelson et al. (2015) examined the extent to which motivation to look at vs. avoid looking at threat and neutral images influenced visual attention to threat in participants high and low in trait anxiety, under counterbalanced calm and anxious mood induction conditions. A unique strength of this study was that eye movements were tracked across $5000 \mathrm{~ms}$ of each image pair exposure (e.g., one threat image paired with one neutral image), thus making it possible to measure changes in attentional deployment to threat over time. After the viewing task, participants rated how motivated they were to look at and how motivated they were to avoid looking at each type of images. They found small to moderate associations between motivation ratings and eye movement indices, which further validated their motivation measures.

When motivation was not considered, results showed a pattern of facilitated attention to threat in $0-1000 \mathrm{~ms}$, followed by almost equal deployment to threat and neutral images from 1000 to $5000 \mathrm{~ms}$. However, results were quite different when motivation was taken into account. 
Participants were divided into groups based on their motivation ratings: those high in motivation to both look at threat and avoid looking at threat were classified as "ambivalent"; those high in motivation to look at threat and low in motivation to avoid looking were classified as "engagers"; those low in motivation to look at threat and high in motivation to avoid were classified as "avoiders"; and those low in motivation to both look at threat and avoid looking were classified as "indifferent". The engagers had a higher proportion of viewing time (PVT) on threat images, whereas the avoiders had a lower PVT on threat images. The indifferent and ambivalent groups had equal PVT on threat and neutral images. However, the ambivalent group had a higher probability of first fixations on the threat image, and had significantly higher trait and state anxiety than did the avoiders and indifferent groups.

Nelson et al. (2015) suggested that those high in trait anxiety may have greater difficulty prioritizing their goals (e.g., to prioritize safety by monitoring the threat vs. to prioritize emotion regulation by avoiding the threat) and were thus ambivalent. Second, whereas participants motivated to engage or avoid threat did so successfully, the ambivalent group may have felt they neither monitored nor avoided threat satisfactorily, hence their greater state anxiety. This is consistent with Healey et al. (2019) and with Kelly et al. (2015) who proposed that poor well-being may be characterized by the inability to manage and prioritize concurrent demands over time, and a subsequent failure to resolve goal conflict.

Nelson et al.'s (2015) findings suggest that there is merit in examining motivation when studying attentional biases to threat. However, there were two major limitations to their study. First, they examined visual deployment to threat images as opposed to an actual threat cue. Although the images were indeed rated as threatening, many images may have lacked personal relevance and situational immediacy, thus posing a significant threat to the ecological validity of their findings. This limitation is not unique to Nelson et al. (2015) but applies to almost all existing studies looking at attentional biases to spiders. Second, when people encounter threat in real life they are likely to have other tasks they need to accomplish (independent from threat), and many of these tasks require considerable attentional resources. If so, anxious individuals are likely to struggle with resolving the competing goals of monitoring threat for safety and performing well on an attentionally demanding task. However, research on this topic is scant (for a review, see Kelly et al. 2015) and in many earlier studies, participants had to engage in tasks that by design involved attending to spider stimuli (e.g., Ohman et al. 2001; Paulitzki et al. 2008; Wilson et al. 2015), which does not reflect real-life encounters of threat.

The current study sought to address Nelson et al.'s (2015) limitations by having spider-fearful individuals perform an attentionally demanding task in the presence of a live tarantula while their eye movements were tracked. Hence, we were able to improve the ecological validity by using actual threat rather than threat images, and creating a situation where threat was task-irrelevant and competed with the current task for attentional resources. We also adopted the free viewing eye movement paradigm from Nelson et al. (2015), thus allowing us to understand attentional biases to threat across the time course (another common limitation of previous studies, see Cisler and Koster 2010). Having addressed these limitations, the present study aimed to extend the findings from Nelson et al. (2015) and Healey et al. (2019) and examine the following questions: (1) do spider-fearful individuals experience ambivalent motivation towards spider; (2) to what extent does ambivalent motivation influence visual attention to spider; and (3) is ambivalent motivation associated with higher spider fear.

Based on Cisler and Koster (2010), Nelson et al. (2015), and Kelly et al. (2015), we further hypothesized that: (1) some spider-fearful individuals would exhibit high motivation to both look at and avoid looking at the spider (that is, would be ambivalent); (2) motivation to look at and avoid looking at the spider would influence visual attention such that the ambivalent group would uniquely show initial facilitated attention to the spider, but would look at the spider less than the engagers and more than the avoiders; and (3) relative to other groups, those who were ambivalent about whether or not to look at the spider would exhibit greater spider fear and more negative affect at the end of the study.

\section{Method}

\section{Participants}

Participants were recruited via posters and an online sign up system from the University of Waterloo and were screened using the Fear of Spiders Questionnaire (FSQ; Szymanski and O'Donohue 1995) administered online. Participants who scored in the top fifteenth percentile on the FSQ (i.e., with a minimum total score of 80 ), which is on par with scores of individuals diagnosed with clinically significant spider phobia (see Muris and Merckelbach 1996), were invited to participate. The final sample consisted of 96 participants (15 males) with a mean age of 19.8 years $(S D=1.4)$. There was no significant gender difference in self-report measures, performance on the Metronome Response Task (MRT), or eye movement indices $\left(p_{s}>0.07\right)$. Participants received course credit or cash remuneration (ten Canadian dollars) in exchange for their participation. The protocol received ethical clearance from the Office of Research Ethics at the University of Waterloo and all participants provided informed consent. 


\section{Self-Report Measures}

Fear of Spiders Questionnaire (FSQ; Szymanski and O'Donohue 1995) The FSQ is an 18-item scale that assesses negative response to and attitudes about spiders, and fear of harm by spiders. Participants rate their agreement with statements on an 8-point Likert scale (from 1 "totally disagree" to 7 "totally agree"). This measure has demonstrated strong psychometric properties (Muris and Merckelbach 1996; Teachman and Woody 2003). It was used to select people high in spider fear.

Positive and Negative Affect Schedule (PANAS; Watson et al. 1988) The PANAS consists of ten items measuring positive affect and ten items measuring negative affect. Using a 5-point Likert scale (from 1 "very slightly or not at all" to 5 "extremely"), participants rated the extent to which each item was consistent with their current mood state. The PANAS has demonstrated good validity and reliability (Crawford and Henry 2004). The PANAS was included to assess participants' mood state at baseline, after introduction to the spider, and at the end of the study.

Subjective Units of Distress Scale (SUDS) This is a 100-point Likert scale on which participants rate how much they fear the spider at that moment from 0 ("No fear whatsoever") to 100 ("An extremely high, intolerable amount of fear"). The SUDS is commonly used in clinical practice (Siegel and Warren 2013) and was included to assess participants' spider fear at baseline, after introduction to the spider, and at the end of the study.

Motivation Ratings Participants were asked to rate the extent that they were motivated to look at the spider, to avoid looking at the spider, and to do well on the MRT. Ratings were made on a 9-point Likert scale ranging from 1 ("no motivation at all") to 9 ("very strong motivation"), at each of the 12 thought probes embedded in the MRT.

\section{Metronome Response Task}

The MRT (Seli et al. 2013) is a sustained-attention task in which participants press a spacebar in time with a metronome. Participants completed 20 practice trials followed by 600 test trials on a computer using the E-Prime software (Psychology Software Tools 2007). Each MRT trial started with $650 \mathrm{~ms}$ of silence, followed by a metronome tone which lasted for $75 \mathrm{~ms}$, and then $575 \mathrm{~ms}$ of silence. As per Xu et al. (2017), thought probes were randomly presented within every block of 50 MRT trials, with the rule that there be a minimum of 10 trials between probes, for a total of 12 probes. At each probe, the task ceased and participants were prompted with a text box on the screen to type in, verbatim, the thought they had in the moment just prior. For the purposes of the current study, they also rated their motivation to look at the spider, to avoid looking at the spider, and to do well on the MRT task. Three independent judges were recruited to code reported thoughts. Each thought was assigned to one of the two categories: (1) spider-related thoughts, e.g., "the spider is moving", and (2) other thoughts, e.g., "which gift card I should choose". Inter-rater reliability (Cohen's kappa) ranged from 0.95 to 0.97 , suggesting excellent reliability across coders. Inter-rater averages were calculated and significant discrepancies were resolved through discussion. The MRT lased approximately $30 \mathrm{~min}$ (excluding the time to calibrate the eye tracker).

\section{Material and Stimuli}

Participants were seated at a table $90 \mathrm{~cm}$ in front of a 15-in. desktop computer monitor and $85 \mathrm{~cm}$ from a $10 \times 10 \times 12 \mathrm{~cm}$ glass terrarium and an $8 \times 8 \times 10 \mathrm{~cm}$ basket, positioned to the left and right of the monitor with an approximately $10^{\circ}$ visual angle, counterbalanced across participants. The terrarium contained a live, Chilean Rose tarantula with a visibly ill-fitting lid and the basket contained a variety of gift cards. Participants were explicitly told that if they responded to at least $90 \%$ of the trials in the MRT, they could choose one of the gift cards from the basket as an additional reward (in reality, every participant was given a gift card). Hence, the basket of gift cards served as a reminder for participants to attend to the MRT, and together with the live spider, they created a situation where participants had to decide on where to deploy their attention (i.e., attending to the spider vs. attending to the current task).

\section{Eye Tracking Procedure}

We used a iView $\mathrm{X}^{\mathrm{TM}}$ head-mounted portable eye tracking device system (SensoMotoric Instruments 2009) to record participants' eye movements during the course of the MRT. Participants had free head movement, although they were instructed to minimize large head movements as this could compromise calibration, rendering the data unusable. Eye movement data was coded using the BeGaze ${ }^{\mathrm{TM}}$ software (SensoMotoric Instruments 2014). The standard settings identifying saccades and fixations were used, such as that a saccade was considered an eye movement that reaches a peak velocity of $40^{\circ}$ per second and this peak velocity must lie within a range of $20-80 \%$ of the distance between start and end; eye movements that did not meet these criteria, did not constitute a blink, and lasted for at least $50 \mathrm{~ms}$ were classified as fixations. 


\section{Procedure}

Participants completed the FSQ online and those with a total score of 80 or higher were invited to participate in this study. Upon their arrival at the lab, participants completed the PANAS and SUDS without the spider present. The researcher then retrieved the glass terrarium containing the spider, placed it in the visual field beside the monitor, and demonstrated that it was real and alive by prodding it gently with a pen to evoke movement. Participants then completed the PANAS and SUDS again, after which they were calibrated on the eye tracker and underwent the MRT. After the MRT, participants completed the PANAS and SUDS for the third time. In total, the procedure lasted roughly $60 \mathrm{~min}$.

\section{Results}

Prior to conducting each analysis, outliers on the dependent measures (i.e., three standard deviations above or below the means) were corrected by replacing them with the next highest or lowest values. Given the small sample size for some of the motivation groups, we conducted post hoc power analyses using the software package $G^{*}$ power3 (Faul et al. 2007) with actual sample size, observed effect size, and $\alpha$ set at 0.05 (two tailed). In addition, as observed effect sizes in small-sample studies can be misleading, we also presented a priori power computations using the same software package $G^{*}$ power3 (Faul et al. 2007) with actual sample size, medium effect size $(d=0.5)$, and $\alpha$ set at 0.05 (two tailed).

\section{Preparing Eye Movement Data}

Eye movement data from 20 participants were unusable due to the following reasons: the eye tracker failed to calibrate (ten participants), tracking ratio of the eye tracker was lower than $50 \%$ (six participants), stimuli of interest were not present in the visual field (three participants), and missing data (one participant). Therefore, there were 76 participants with available eye movement data for analyses, including 12 ambivalent, 15 engagers, 18 avoiders, and 31 indifferent.

Eye tracking was interrupted 12 times by the thought probes. Given that it was possible for the first probe to occur very shortly after the start of the task and the last probe very close to the end of the task, we opted to discard data from the beginning of the MRT to the start of the first probe and that from the end of the final probe to the end of the task. We also encountered an intractable technical problem with $\mathrm{BeGaze}^{\mathrm{TM}}$ software such that it was impossible to access data between the eleventh and twelfth thought probes for 15 participants. We thus opted not to include this segment in our analyses. Therefore, there were 10 segments of eye movement data for each participant. We defined two areas of interest (AOI), which were the terrarium containing the spider and the basket containing the gift cards. For each AOI, we generated the following eye movement indices: (1) probability of first fixation (PFF) on a particular AOI in the beginning of any given segment; (2) first fixation duration (FFD), which reflects the average duration of the first fixations on a particular AOI; and (3) PVT, which reflects the percentage of time spent on looking at a particular AOI. It should be noted that the PFF and PVT percentages do not add up to $100 \%$ because participants were allowed to look freely and they did look at other objects in the room (e.g., the blank monitor, the wall, etc.).

In addition, we calculated a bias score for each of the eye movement indices listed above. For example, we calculated the PFF bias score by subtracting the PFF on gift cards from the PFF on the spider for each participant per segment. Likewise, we calculated the FFD bias score and the PVT bias score using the same algorithm.

\section{Preparing Response Time Data (for the Metronome Response Task)}

The Rhythmic Response Time (RRT) was first calculated as the absolute difference between the time of the key-press and the onset of the metronome tone. A higher RRT variance indicates less synchronous responding, which in turn reflects poorer performance (Seli et al. 2015a, b). Variance data was highly skewed in the positive direction, which is typical to studies using the MRT. Hence, we followed established procedures and adjusted the RRT variance using a natural logarithm transform (see Seli et al. 2013). Mean RRT variance was calculated by using a moving window of the current and preceding four trials across all trials except the very first five trials and the five trials following each thought probe. Mean RRT variance serves as an indicator of participants' overall performance on the MRT. We also calculated the proportion of spider-related thoughts for each participant, which indicates the extent to which participants were distracted by the tarantula during the MRT.

\section{Did Individuals Vary in Their Motivation to Look at vs. Avoid Looking at the Spider?}

Overall ratings of motivation to look at and to avoid looking at the spider, and overall motivation to do well on the MRT task were calculated by summing ratings across the 12 thought probes. Means and standard deviations are presented in Table 1. The correlation between motivation to look at the spider and to avoid looking at the spider was almost zero, $r=-0.01, p=0.958$. Motivation to do well on the task had a small but significant correlation with motivation to avoid looking at the spider, $r=0.249, p=0.015$, but not with motivation to look at the spider, $r=0.071, p=0.490$. The 
Table 1 Motivation ratings by group

\begin{tabular}{lllll}
\hline & $N$ & $\begin{array}{l}\text { Motivation to } \\
\text { look at spider }\end{array}$ & $\begin{array}{l}\text { Motivation to } \\
\text { avoid looking } \\
\text { at spider }\end{array}$ & $\begin{array}{l}\text { Motivation } \\
\text { to do well on } \\
\text { task }\end{array}$ \\
\hline All participants & 96 & $4.24(2.28)$ & $4.50(2.59)$ & $7.77(1.40)$ \\
Ambivalent & 16 & $6.96(1.21)$ & $7.22(1.24)$ & $8.29(0.77)$ \\
Engagers & 18 & $6.74(1.18)$ & $2.42(1.21)$ & $7.58(1.53)$ \\
Avoiders & 22 & $2.47(1.16)$ & $7.44(1.03)$ & $8.10(1.23)$ \\
Indifferent & 40 & $3.01(1.23)$ & $2.73(1.21)$ & $7.47(1.56)$ \\
\hline
\end{tabular}

Note: Standard deviations from the mean are presented in brackets

correlation coefficients among motivation ratings, self-report ratings (including FSQ, mood states, spider fear), overall eye movement indices, and MRT performance measures are presented in Table 2. In general, motivation ratings appear to have small to moderate associations with self-report ratings, overall eye movement indices, and performance measures on the MRT.

We divided our sample into four groups based on their ratings to look at vs. avoid looking at the spider, as per Nelson et al. (2015): (1) ambivalent, i.e., those who scored 5 or above on both motivation to look at the spider and motivation to avoid looking at it $(N=16)$; (2) engagers, i.e., those who scored 5 or above on motivation to look at the spider and below 5 on motivation to avoid looking at it $(N=18)$; (3) avoiders, i.e., those who scored 5 or above on motivation to avoid looking at the spider and below 5 on motivation to look at it $(N=22)$; and (4) indifferent, i.e., those who scored below 5 on both motivation to look at the spider and motivation to avoid looking at it $(N=40)$. In addition, oneway ANOVAs revealed no main effect of group for performance motivation or FSQ score, $p_{s}>0.135$, suggesting that all groups were equally motivated to perform well on the task and reported similar levels of spider fear at baseline.

Our first hypothesis was thus confirmed: a subset of our sample reported ambivalent motivation towards the spider. Overall, motivation to look at the spider was independent from motivation to avoid looking at the spider.

\section{Did Overall Visual Attention to the Spider Vary According to Motivation?}

Means and standard deviations of overall eye movement indices are presented in Table 3. We first conducted a 2 (Stimulus: spider vs. gift cards) $\times 4$ (Group: ambivalent vs. engagers vs. avoiders vs. indifferent) mixed ANOVA on probability of first fixation (PFF). This analysis revealed a significant main effect of stimulus, $F(1,71)=43.18$, $\eta_{\mathrm{p}}^{2}=0.378, p<0.001$, observed power $=1.00$, a priori power $=1.00$ (assuming $d=0.5$ ); a significant main effect of group, $F(3,71)=18.39, \eta_{\mathrm{p}}^{2}=0.437, p<0.001$, observed
Table 2 Correlations among motivation ratings, self-report ratings, overall eye movement indices, and MRT performance measures

\begin{tabular}{|c|c|c|c|}
\hline & \multicolumn{3}{|l|}{ Motivation } \\
\hline & Look at spider & $\begin{array}{l}\text { Avoid } \\
\text { looking at } \\
\text { spider }\end{array}$ & Do well on task \\
\hline \multicolumn{4}{|l|}{ Motivation } \\
\hline $\begin{array}{l}\text { Avoid looking at } \\
\text { spider }\end{array}$ & -0.01 & & \\
\hline Do well on task & 0.07 & $0.25 *$ & \\
\hline FSQ total score & -0.10 & -0.01 & -0.07 \\
\hline \multicolumn{4}{|l|}{ Spider fear } \\
\hline $\mathrm{T} 1$ & 0.12 & $0.35^{* *}$ & 0.08 \\
\hline $\mathrm{T} 2$ & 0.17 & $0.51 * *$ & 0.10 \\
\hline $\mathrm{T} 3$ & $0.34 * *$ & $0.59 * *$ & $0.22 *$ \\
\hline \multicolumn{4}{|l|}{ Positive affect } \\
\hline $\mathrm{T} 1$ & 0.17 & -0.13 & $0.41 * *$ \\
\hline $\mathrm{T} 2$ & 0.12 & $-0.21^{*}$ & $0.31^{*}$ \\
\hline T3 & $0.20 *$ & 0.02 & $0.47 * *$ \\
\hline \multicolumn{4}{|l|}{ Negative affect } \\
\hline $\mathrm{T} 1$ & $0.24 *$ & $0.20^{*}$ & -0.11 \\
\hline $\mathrm{T} 2$ & 0.19 & $0.44 * *$ & -0.02 \\
\hline $\mathrm{T} 3$ & $0.44 * *$ & $0.48 * *$ & 0.19 \\
\hline \multicolumn{4}{|c|}{ Overall eye movement indices } \\
\hline PFF spider (\%) & $0.51 * *$ & $-0.31 * *$ & -0.18 \\
\hline PFF gift cards (\%) & -0.15 & -0.19 & -0.10 \\
\hline FFD spider (ms) & 0.14 & -0.12 & 0.08 \\
\hline FFD gift cards (ms) & 0.10 & 0.01 & 0.14 \\
\hline PVT spider $(\%)$ & $0.54 * *$ & -0.18 & 0.17 \\
\hline PVT gift cards (\%) & 0.00 & -0.22 & 0.00 \\
\hline Mean RRT variance & 0.12 & -0.07 & 0.01 \\
\hline $\begin{array}{l}\text { Proportion of spider- } \\
\text { related thoughts \% }\end{array}$ & $0.57 * *$ & 0.05 & 0.06 \\
\hline
\end{tabular}

Note: $F S Q$ fear of spiders questionnaire, $T 1$ baseline, $T 2$ after introduction to spider, $T 3$ at end of study, $P V T$ proportion of viewing time, $F F D$ first fixation duration, $P F F$ probability of first fixation, $R R T$ rhythmic response time. ${ }^{*} p<0.05, * * p<0.01$

power $=1.00$, a priori power $=1.00$ (assuming $d=0.5)$; and a significant stimulus by group interaction, $F(3,71)=20.84$, $\eta_{\mathrm{p}}^{2}=0.468, p<0.001$, observed power $=1.00$, a priori power $=1.00$ (assuming $d=0.5$ ). Follow-up paired-sample t-tests showed that first fixations were more likely to land on the spider than gift cards for the ambivalent group, $t$ $(11)=2.93, p=0.015$, observed power $=0.75$, a priori power $=0.35$ (assuming $d=0.5$ ), and engagers group, $t$ $(14)=4.61, p<0.001$, observed power $=0.98$, a priori power $=0.44$ (assuming $d=0.5$ ), but not for the indifferent group, $t(30)=0.69, p=0.498$, observed power $=0.10$, a priori power $=0.77$ (assuming $d=0.5$ ). First fixations in the avoider group were neither on the spider nor on the gift cards. 
Table 3 Overall eye movement indices by group

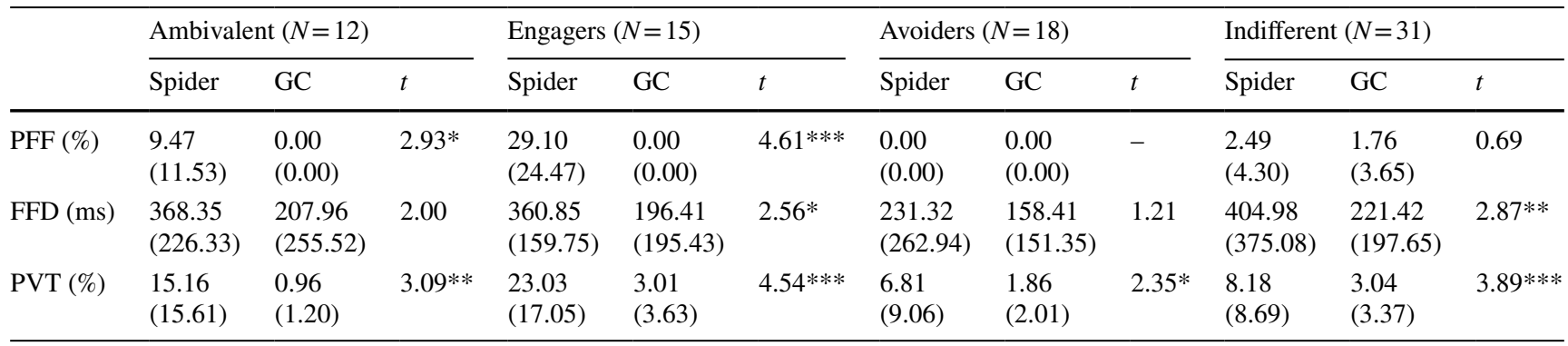

Note: Standard deviations from the mean are presented in brackets. $G C$ gift cards, $P F F$ probability of first fixation, $F F D$ first fixation duration, $P V T$ proportion of viewing time. Paired-sample t-tests were performed to examine between-group differences. ${ }^{*} p<0.05, * * p<0.01$, $* * * p<0.001$

We also conducted the same 2 (Stimulus: spider vs. gift cards) $\times 4$ (Group: ambivalent vs. engagers vs. avoiders vs. indifferent) mixed ANOVA on FFD. We observed a significant main effect of stimulus, $F(1,72)=15.42, \eta^{2}{ }_{\mathrm{p}}=0.176$, $p<0.001$, observed power $=0.99$, a priori power $=1.00$ (assuming $d=0.5)$; no main effect of group, $F(3,72)=1.35$, $\eta_{\mathrm{p}}^{2}=0.053, p=0.266$, observed power $=0.53$, a priori power $=1.00$ (assuming $d=0.5$ ); and no stimulus by group interaction, $F(3,72)=0.53, \eta_{\mathrm{p}}^{2}=0.022, p=0.664$, observed power $=0.42$, a priori power $=1.00$ (assuming $d=0.5$ ). Follow-up paired-sample t-tests showed that first fixations were significantly longer on the spider than gift certificates for the engagers group, $t(14)=2.56, p=0.023$, observed power $=0.66$, a priori power $=0.44$ (assuming $d=0.5$ ), and indifferent group, $t(30)=2.87, p=0.007$, observed power $=0.79$, a priori power $=0.77$ (assuming $d=0.5$ ), but not for the avoiders group, $t(17)=1.21, p=0.243$, observed power $=0.21$, a priori power $=0.52$ (assuming $d=0.5)$, or ambivalent group, $t(11)=2.00, p=0.071$, observed power $=0.44$, a priori power $=0.35$ (assuming $d=0.5$ ).

Lastly, we conducted a 2 (Stimulus: spider vs. gift cards) $\times 4$ (Group: ambivalent vs. engagers vs. avoiders vs. indifferent) mixed ANOVA on PVT. This analysis revealed a significant main effect of stimulus, $F(1,72)=60.32$, $\eta_{\mathrm{p}}^{2}=0.456, p<0.001$, observed power $=1.00$, a priori power $=1.00$ (assuming $d=0.5$ ); a significant main effect of group, $F(3,72)=5.85, \eta_{\mathrm{p}}^{2}=0.196, p=0.001$, observed power $=0.99$, a priori power $=1.00($ assuming $d=0.5)$; and a significant stimulus by group interaction, $F(3,72)=7.04$, $\eta_{\mathrm{p}}^{2}=0.227, p<0.001$, observed power $=1.00$, a priori power $=1.00$ (assuming $d=0.5$ ). Follow-up paired-sample t-tests showed that all participants spent more time viewing the spider than gift cards (all $p_{\mathrm{s}}<0.031$; observed power $=0.80$ for ambivalent, 0.98 for engagers, 0.60 for avoiders, and 0.96 for indifferent; a priori power $=0.35$ for ambivalent, 0.44 for engagers, 0.52 for avoiders, and 0.77 for indifferent, assuming $d=0.5$ ).

In addition, we performed multiple one-way ANOVAs in which PFF bias score, FFD bias score, and PVT bias score were each tested as a function of group (ambivalent vs. engagers vs. avoiders vs. indifferent). For PFF bias score, we observed a significant main effect of group, $F$ (3, $71)=20.84, \eta_{\mathrm{p}}^{2}=0.468, p<0.001$, observed power $=1.00$, a priori power $=0.96$ (assuming $d=0.5$ ). Post hoc comparisons (Tukey's HSD) revealed that the engagers group had a significantly higher PFF bias score than all other groups (all $p_{\mathrm{s}}<0.002$; observed power $=1.00$ for engagers vs. avoiders, 1.00 for engagers vs. ambivalent, and 1.00 for engagers vs. indifferent; a priori power $=0.28$ for engagers vs. avoiders, 0.23 for engagers vs. ambivalent, and 0.34 for engagers vs. indifferent, assuming $d=0.5$ ). For FFD bias score, we observed no significant main effect of group, $F(3,72)=0.52, \eta_{\mathrm{p}}^{2}=0.022, p=0.664$, observed power $=0.16$, a priori power $=0.96$ (assuming $d=0.5$ ). For PVT bias score, we observed a significant main effect of group, $F(3,71)=7.04, \eta_{\mathrm{p}}^{2}=0.227, p<0.001$, observed power $=0.98$, a priori power $=0.96$ (assuming $d=0.5$ ). Post hoc comparisons (Tukey's HSD) revealed that the engagers group had a significantly higher PVT bias score than the avoiders and indifferent groups (both $p_{\mathrm{s}}<0.002$; observed power $=1.00$ for engagers vs. avoiders, and 1.00 for engagers vs. indifferent; a priori power $=0.28$ for engagers vs. avoiders, and 0.34 for engagers vs. indifferent, assuming $d=0.5$ ), but there was no significant difference between the engagers and ambivalent group $(p=0.576$; observed power $=0.89$; a priori power $=0.24$, assuming $d=0.5$ ).

These findings provide some support to our hypothesis that the ambivalent group would display a unique pattern of visual attention to threat. Similar to the engagers group, ambivalent individuals were more likely to have their first fixations on the spider than gift cards. While the engagers group had longer first fixations on the spider than gift cards, such difference was not observed among ambivalent individuals. Among all four groups, the engagers demonstrated the most robust attentional bias to threat. 


\section{Did Visual Attention to the Spider Vary Over Time According to Motivation?}

Means and standard errors of segment-specific eye movement indices are presented in Table 4 . We first conducted a 2 (Stimulus: spider vs. gift cards) $\times 4$ (Group: ambivalent vs. engagers vs. avoiders vs. indifferent) $\times 10$ (Time: S1-S10) repeated measures ANOVA on PVT. Mauchly's test indicated that the assumption of sphericity had been violated for main effect of time, $\chi^{2}(44)=174.15, p<0.001$, and stimulus by time interaction, $\chi^{2}(44)=181.84, p<0.001$, therefore degrees of freedom were corrected using Huynh-Feldt estimates of sphericity ( $\varepsilon=0.679$ for time, and $\varepsilon=0.681$ for stimulus by time). This analysis revealed a main effect of stimulus, $F(1,72)=62.36, \eta_{\mathrm{p}}^{2}=0.464, p<0.001$, observed power $=1.00$, a priori power $=1.00($ assuming $d=0.5)$; a main effect of time, $F(6.11,439.86)=3.84, \eta_{\mathrm{p}}^{2}=0.051$, $p<0.001$, observed power $=0.99$, a priori power $=1.00$ (assuming $d=0.5)$; a main effect of group, $F(3,72)=10.59$, $\eta_{\mathrm{p}}^{2}=0.306, p<0.001$, observed power $=1.00$, a priori power $=1.00$ (assuming $d=0.5$ ); a stimulus by group interaction, $F(3,72)=11.90, \eta_{\mathrm{p}}^{2}=0.332, p<0.001$, observed power $=0.99$, a priori power $=1.00$ (assuming $d=0.5)$; a time by group interaction, $F(18.33,439.86)=3.03$, $\eta_{\mathrm{p}}^{2}=0.112, p<0.001$, observed power $=1.00$, a priori power $=1.00$ (assuming $d=0.5$ ); a stimulus by time interaction, $F(6.13,441.50)=3.51, \eta_{\mathrm{p}}^{2}=0.046, p=0.002$, observed power $=0.99$, a priori power $=1.00$ (assuming $d=0.5)$; and a stimulus by time by group interaction, $F$ $(18.40,441.50)=4.03, \eta_{p}^{2}=0.144, p<0.001$, observed power $=1.00$, a priori power $=1.00($ assuming $d=0.5)$.

To explore this three-way interaction, we calculated the proportion viewing time (PVT) bias score by subtracting the PVT on gift cards from the PVT on the spider for each participant per segment. A PVT bias score that is significantly greater than 0 was thus indicative of an attentional bias towards the spider. Likewise, a PVT bias score that is significantly lower than 0 was indicative an attentional bias towards gift cards. Means and standard errors of PVT bias scores are depicted in Fig. 1.

To explore if different motivation groups demonstrated different time courses of eye movements, we performed multiple one-way ANOVAs in which PVT bias score was tested as a function of group (ambivalent vs. engagers vs. avoiders vs. indifferent) within each segment. We observed a significant main effect of group during $\mathrm{S} 1, F(3$, $72)=7.97, \eta_{\mathrm{p}}^{2}=0.249, p<0.001$, observed power $=0.99$, a priori power $=0.96($ assuming $d=0.5) ; \mathrm{S} 2, F(3,72)=6.86$, $\eta_{\mathrm{p}}^{2}=0.222, p<0.001$, observed power $=0.97$, a priori power $=0.96$ (assuming $d=0.5)$; S3, $F(3,72)=7.01$, $\eta_{\mathrm{p}}^{2}=0.226, p<0.001$, observed power $=0.98$, a priori power $=0.96$ (assuming $d=0.5) ; \mathrm{S} 4, F(3,72)=8.78$, $\eta_{\mathrm{p}}^{2}=0.268, p<0.001$, observed power $=0.99$, a priori power $=0.96$ (assuming $d=0.5)$; S5, $F(3,72)=7.73$, $\eta_{\mathrm{p}}^{2}=0.244, p<0.001$, observed power $=0.98$, a priori power $=0.96$ (assuming $d=0.5)$; S6, $F(3,72)=3.87$, $\eta_{\mathrm{p}}^{2}=0.139, p=0.013$, observed power $=0.82$, a priori power $=0.96$ (assuming $d=0.5)$; S7, $F(3,72)=11.98$, $\eta_{\mathrm{p}}^{2}=0.333, p<0.001$, observed power $=1.00$, a priori power $=0.96$ (assuming $d=0.5)$; S8, $F(3,72)=13.35$, $\eta_{\mathrm{p}}^{2}=0.357, p<0.001$, observed power $=1.00$, a priori power $=0.96$ (assuming $d=0.5)$; S9, $F(3,72)=8.47$, $\eta_{\mathrm{p}}^{2}=0.261, p<0.001$, observed power $=0.99$, a priori power $=0.96$ (assuming $d=0.5)$; but not during $\mathrm{S} 10, F(3$, $72)=1.44, \eta_{\mathrm{p}}^{2}=0.057, p=0.239$, observed power $=0.38$, a priori power $=0.96$ (assuming $d=0.5)$.

Table 4 Segment-specific eye movement indices by group

\begin{tabular}{|c|c|c|c|c|c|c|c|c|c|c|c|}
\hline Index & Group & $\mathrm{S} 1$ & S2 & $\mathrm{S} 3$ & $\mathrm{~S} 4$ & S5 & S6 & S7 & S8 & S9 & S10 \\
\hline \multirow[t]{4}{*}{$\begin{array}{l}\text { PVT } \\
\text { Spider (\%) }\end{array}$} & $\begin{array}{l}\text { Ambivalent } \\
(N=12)\end{array}$ & $\begin{array}{l}12.61 \\
(13.80)\end{array}$ & $\begin{array}{l}12.63 \\
(17.21)\end{array}$ & $\begin{array}{l}24.57 \\
(34.01)\end{array}$ & $\begin{array}{l}26.28 \\
(27.94)\end{array}$ & $\begin{array}{l}8.51 \\
(11.11)\end{array}$ & $\begin{array}{l}3.35 \\
(3.37)\end{array}$ & $\begin{array}{l}6.73 \\
(7.29)\end{array}$ & $\begin{array}{l}6.37 \\
(6.54)\end{array}$ & $\begin{array}{l}3.63 \\
(5.10)\end{array}$ & $\begin{array}{l}5.17 \\
(6.94)\end{array}$ \\
\hline & $\begin{array}{l}\text { Engagers } \\
(N=15)\end{array}$ & $\begin{array}{l}26.03 \\
(26.69)\end{array}$ & $\begin{array}{l}30.95 \\
(28.99\end{array}$ & $\begin{array}{l}23.51 \\
(18.74)\end{array}$ & $\begin{array}{l}19.34 \\
(16.49)\end{array}$ & $\begin{array}{l}27.22 \\
(34.36)\end{array}$ & $\begin{array}{l}13.89 \\
(16.11)\end{array}$ & $\begin{array}{l}27.29 \\
(29.18)\end{array}$ & $\begin{array}{l}30.94 \\
(29.21)\end{array}$ & $\begin{array}{l}25.88 \\
(28.17)\end{array}$ & $\begin{array}{l}16.52 \\
(17.59)\end{array}$ \\
\hline & $\begin{array}{l}\text { Avoiders } \\
(N=18)\end{array}$ & $\begin{array}{l}2.37 \\
(3.00)\end{array}$ & $\begin{array}{l}3.71 \\
(4.24)\end{array}$ & $\begin{array}{l}6.31 \\
(9.44)\end{array}$ & $\begin{array}{l}1.94 \\
(2.56)\end{array}$ & $\begin{array}{l}0.56 \\
(0.64)\end{array}$ & $\begin{array}{l}3.44 \\
(4.82)\end{array}$ & $\begin{array}{l}3.11 \\
(4.59)\end{array}$ & $\begin{array}{l}5.29 \\
(7.62)\end{array}$ & $\begin{array}{l}5.71 \\
(7.54)\end{array}$ & $\begin{array}{l}7.81 \\
(10.61)\end{array}$ \\
\hline & $\begin{array}{l}\text { Indifferent } \\
(N=31)\end{array}$ & $\begin{array}{l}7.05 \\
(9.52)\end{array}$ & $\begin{array}{l}9.61 \\
(13.99)\end{array}$ & $\begin{array}{l}6.12 \\
(7.91)\end{array}$ & $\begin{array}{l}7.96 \\
(10.84)\end{array}$ & $\begin{array}{l}7.86 \\
(10.62)\end{array}$ & $\begin{array}{l}4.41 \\
(6.27)\end{array}$ & $\begin{array}{l}4.39 \\
(5.23)\end{array}$ & $\begin{array}{l}6.60 \\
(8.19)\end{array}$ & $\begin{array}{l}6.48 \\
(8.35)\end{array}$ & $\begin{array}{l}11.53 \\
(16.13)\end{array}$ \\
\hline \multirow[t]{4}{*}{$\begin{array}{l}\text { PVT } \\
\text { GC (\%) }\end{array}$} & $\begin{array}{l}\text { Ambivalent } \\
(N=12)\end{array}$ & $\begin{array}{l}0.58 \\
(0.91)\end{array}$ & $\begin{array}{l}0.17 \\
(0.25)\end{array}$ & $\begin{array}{l}0.43 \\
(0.66)\end{array}$ & $\begin{array}{l}0.62 \\
(0.65)\end{array}$ & $\begin{array}{l}0.13 \\
(0.23)\end{array}$ & $\begin{array}{l}0.43 \\
(0.79)\end{array}$ & $\begin{array}{l}0.00 \\
(0.00)\end{array}$ & $\begin{array}{l}2.56 \\
(3.95)\end{array}$ & $\begin{array}{l}0.68 \\
(1.02)\end{array}$ & $\begin{array}{l}0.43 \\
(0.53)\end{array}$ \\
\hline & $\begin{array}{l}\text { Engagers } \\
(N=15)\end{array}$ & $\begin{array}{l}2.20 \\
(2.73)\end{array}$ & $\begin{array}{l}2.28 \\
(3.57)\end{array}$ & $\begin{array}{l}1.38 \\
(1.98)\end{array}$ & $\begin{array}{l}3.47 \\
(5.11)\end{array}$ & $\begin{array}{l}1.73 \\
(2.27)\end{array}$ & $\begin{array}{l}2.53 \\
(3.12)\end{array}$ & $\begin{array}{l}0.47 \\
(0.70)\end{array}$ & $\begin{array}{l}0.76 \\
(0.99)\end{array}$ & $\begin{array}{l}1.68 \\
(2.23)\end{array}$ & $\begin{array}{l}2.78 \\
(3.91)\end{array}$ \\
\hline & $\begin{array}{l}\text { Avoiders } \\
(N=18)\end{array}$ & $\begin{array}{l}0.33 \\
(0.51)\end{array}$ & $\begin{array}{l}0.54 \\
(0.70)\end{array}$ & $\begin{array}{l}1.41 \\
(1.95)\end{array}$ & $\begin{array}{l}1.89 \\
(2.98)\end{array}$ & $\begin{array}{l}2.64 \\
(4.24)\end{array}$ & $\begin{array}{l}1.23 \\
(1.68)\end{array}$ & $\begin{array}{l}0.99 \\
(1.42)\end{array}$ & $\begin{array}{l}1.07 \\
(1.77)\end{array}$ & $\begin{array}{l}1.30 \\
(1.24)\end{array}$ & $\begin{array}{l}2.43 \\
(3.06)\end{array}$ \\
\hline & $\begin{array}{l}\text { Indifferent } \\
(N=31)\end{array}$ & $\begin{array}{l}1.81 \\
(2.67)\end{array}$ & $\begin{array}{l}1.38 \\
(1.82)\end{array}$ & $\begin{array}{l}2.24 \\
(3.31)\end{array}$ & $\begin{array}{l}2.98 \\
(4.22)\end{array}$ & $\begin{array}{l}1.18 \\
(1.78)\end{array}$ & $\begin{array}{l}1.60 \\
(2.25)\end{array}$ & $\begin{array}{l}4.23 \\
(5.84)\end{array}$ & $\begin{array}{l}3.30 \\
(4.02)\end{array}$ & $\begin{array}{l}1.03 \\
(1.24)\end{array}$ & $\begin{array}{l}2.00 \\
(2.74)\end{array}$ \\
\hline
\end{tabular}

Note: Standard deviations from the mean are presented in brackets. $G C$ gift cards, $P V T$ proportion of viewing time 


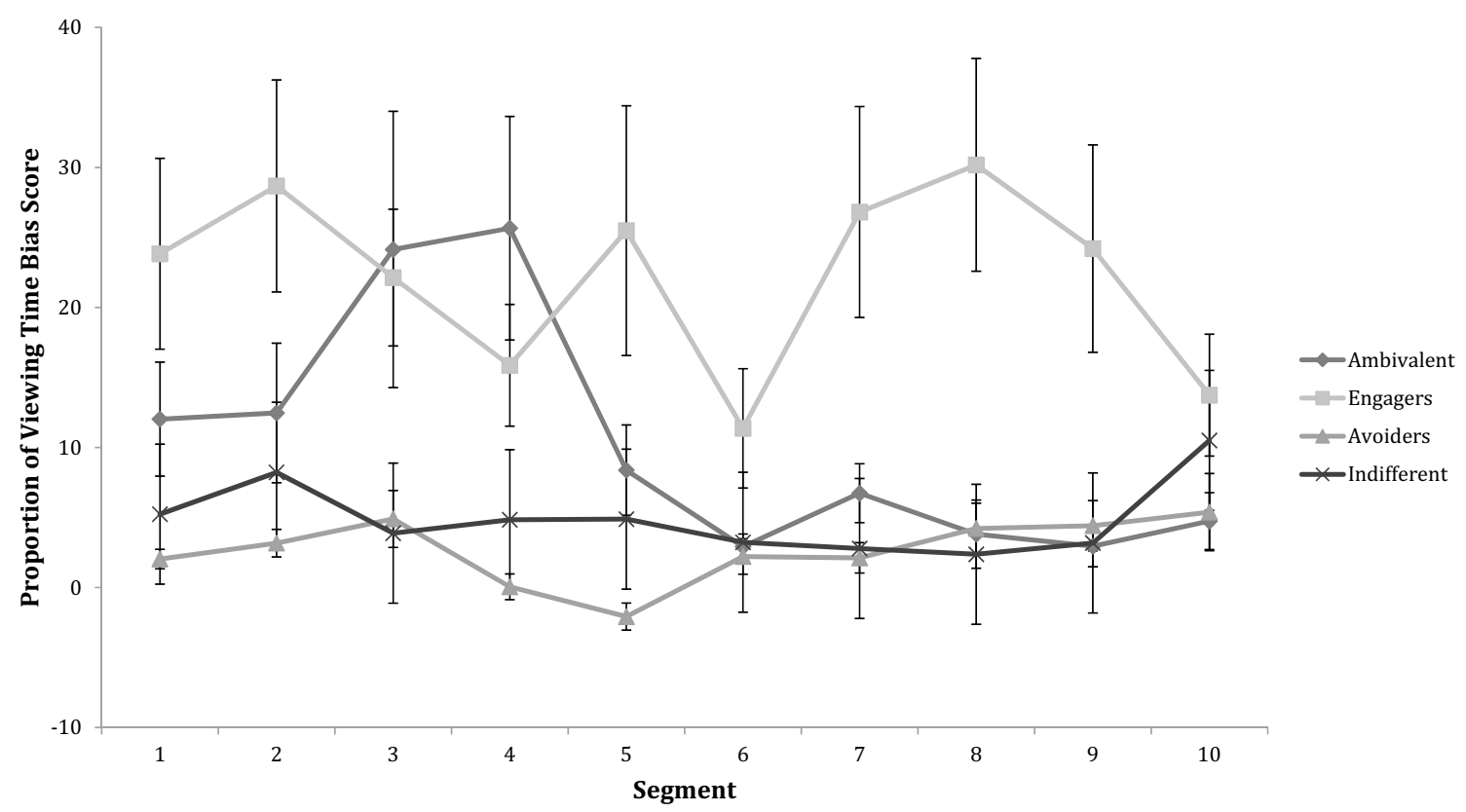

Fig. 1 Proportion of viewing time bias scores across group and segment. Note: Error bars represent \pm 1 standard error

Interestingly, post hoc comparisons (Tukey's HSD) showed that the ambivalent group had a sudden increase in their PVT bias score during S3-S4, which was not observed in other groups. During S1-S2, there was no significant difference in PVT bias score between the ambivalent group and all other groups (all $p_{\mathrm{s}}>0.077$; observed power $=0.28 / 0.38$ for ambivalent vs. engagers during $\mathrm{S} 1 /$ S2, 0.72/0.48 for ambivalent vs. avoiders during S1/S2, and $0.39 / 0.12$ for ambivalent vs. indifferent during S1/S2; a priori power $=0.24$ for ambivalent vs. engagers, 0.25 for ambivalent vs. avoiders, and 0.30 for ambivalent vs. indifferent, assuming $d=0.5$ ), while the engagers group had a higher PVT bias score than avoiders and indifferent groups (all $p_{\mathrm{s}}<0.002$; observed power $=0.89 / 0.92$ for engagers vs. avoiders during $\mathrm{S} 1 / \mathrm{S} 2$, and $0.83 / 0.79$ for engagers vs. indifferent during $\mathrm{S} 1 / \mathrm{S} 2$; a priori power $=0.28$ for engagers vs. avoiders, and 0.34 for engagers vs. indifferent, assuming $d=0.5$ ). However, during S3-S4, the ambivalent group had a higher PVT bias score than avoiders and indifferent groups (all $p_{\mathrm{s}}<0.018$; observed power $=0.51 / 0.91$ for ambivalent vs. avoiders during $\mathrm{S} 3 / \mathrm{S} 4$, and $0.64 / 0.80$ for ambivalent vs. indifferent during $\mathrm{S} 3 / \mathrm{S} 4$; a priori power $=0.25$ for ambivalent vs. avoiders, and 0.30 for ambivalent vs. indifferent, assuming $d=0.5$ ) and there was no significant difference in PVT bias score between ambivalent group and engagers group (both $p_{\mathrm{s}}>0.345$; observed power $=0.05$ during $\mathrm{S} 3$, and 0.18 during $\mathrm{S} 4$; a priori power $=0.24$, assuming $d=0.5$ ), while the engagers group continued to have a higher PVT bias score than avoiders and indifferent groups (all $p_{\mathrm{s}}<0.026$; observed power $=0.90 / 0.94$ for engagers vs. avoiders during S3/S4, and 0.97/0.66 for engagers vs. indifferent during S3/S4; a priori power $=0.28$ for engagers vs. avoiders, and 0.34 for engagers vs. indifferent, assuming $d=0.5$ ). During S5-S6, there was again no significant difference in PVT bias score between ambivalent group and all other groups (all $p_{\mathrm{s}}>0.055$; observed power $=0.38 / 0.42$ for ambivalent vs. engagers during S5/S6, 0.49/0.07 for ambivalent vs. avoiders during S5/S6, and 0.17/0.05 for ambivalent vs. indifferent during S5/S6; a priori power $=0.24$ for ambivalent vs. engagers, 0.25 for ambivalent vs. avoiders, and 0.30 for ambivalent vs. indifferent, assuming $d=0.5$ ), while the engagers group continued to have a higher PVT bias score than avoiders and indifferent groups (all $p_{\mathrm{s}}<0.021$; observed power $=0.75 / 0.54$ for engagers vs. avoiders during S5/S6, and 0.71/0.53 for engagers vs. indifferent during $\mathrm{S} 5 / \mathrm{S} 6$; a priori power $=0.28$ for engagers vs. avoiders, and 0.34 for engagers vs. indifferent, assuming $d=0.5$ ). During S7-S9, the engagers group had a higher PVT bias score than all other groups (all $p_{\mathrm{s}}<0.002$; observed power $=0.90 / 0.91 / 0.74$ for engagers vs. avoiders during S7/ S8/S9, 0.65/0.85/0.72 for engagers vs. ambivalent during S7/ S8/S9, and 0.94/0.98/0.87 for engagers vs. indifferent during $\mathrm{S} 7 / \mathrm{S} 8 / \mathrm{S} 9$; a priori power $=0.28$ for engagers vs. avoiders, 0.24 for engagers vs. ambivalent, and 0.34 for engagers vs. indifferent, assuming $d=0.5$ ). During S10, there was no significant difference in PVT bias score between the engagers group and all other groups (all $p_{\mathrm{s}}>0.335$; observed power $=0.36$ for engagers vs avoiders, 0.41 for engagers vs. ambivalent, and 0.09 for engagers vs. indifferent; a priori power $=0.28$ for engagers vs. avoiders, 0.24 for engagers vs. 
ambivalent, and 0.34 for engagers vs. indifferent, assuming $d=0.5$ ).

Taken together, these results provide partial support to our second set of hypotheses that the ambivalent group looked at the spider less than the engagers and more than the avoiders, but this was only present during the third and fourth segments. In all other segments (except the last segment), the engagers group continued to demonstrate the most robust attentional bias to threat.

\section{Did Spider Fear, Positive Affect, and Negative Affect Differ According to Motivation?}

We hypothesized that the ambivalent group would, uniquely, have greater spider fear and more negative affect at the end of the study than other groups. Means and standard deviations of spider fear, positive affect, and negative affect across group and time are presented in Table 5.

We first conducted a 3 (time 1 vs. time 2 vs. time 3 ) $\times 4$ (ambivalent vs. engagers vs. avoiders vs. indifferent) mixed ANOVA on spider fear ratings. There was a main effect of time, $F(2,184)=68.91, \eta_{\mathrm{p}}^{2}=0.428, p<0.001$, observed power $=1.00$, a priori power $=1.00$ (assuming $d=0.5$ ); a main effect of group, $F(3,92)=11.33, \eta_{\mathrm{p}}^{2}=0.270$, $p<0.001$, observed power $=0.99$, a priori power $=1.00$ (assuming $d=0.5$ ); and a time by group interaction, $F(6$, $184)=4.65, \eta_{\mathrm{p}}^{2}=0.132, p<0.001$, observed power $=1.00$, a priori power $=1.00$ (assuming $d=0.5$ ). To explore this interaction, we conducted one-way ANOVAs at each time point. There was a main effect of group on spider fear after initial introduction of the spider $F(3,92)=8.31, \eta_{\mathrm{p}}^{2}=0.213$, $p<0.001$, observed power $=0.99$, a priori power $=0.99$ (assuming $d=0.5$ ); and at the end of the study, $F$ (3, $92)=18.41, \eta_{\mathrm{p}}^{2}=0.375, p<0.001$, observed power $=1.00$, a priori power $=0.99$ (assuming $d=0.5$ ); but not at baseline, $F$ $(3,92)=2.22, \eta_{\mathrm{p}}^{2}=0.067, p=0.091$, observed power $=0.56$, a priori power $=0.99$ (assuming $d=0.5$ ). Post hoc comparisons (Tukey's HSD) revealed that after the initial introduction of the spider, the avoiders and ambivalent groups reported significantly higher spider fear than the indifferent group (both $p_{\mathrm{s}}<0.001$; observed power $=0.97$ for avoiders vs. indifferent, and 0.98 for ambivalent vs. indifferent; a priori power $=0.46$ for avoiders vs. indifferent, and 0.38 for ambivalent vs. indifferent, assuming $d=0.5$ ). However, at the end of the study, the ambivalent group reported significantly higher spider fear than all other groups (all $p_{\mathrm{s}}<0.007$; observed power $=0.99$ for ambivalent vs. engagers, 0.80 for ambivalent vs. avoiders, and 1.00 for ambivalent vs. indifferent; a priori power $=0.29$ for ambivalent vs. engagers, 0.32 for ambivalent vs. avoiders, and 0.38 for ambivalent vs. indifferent, assuming $d=0.5$ ).

We then conducted the same 3 (time 1 vs. time 2 vs. time 3$) \times 4$ (ambivalent vs. engagers vs. avoiders vs. indifferent) mixed ANOVA on positive affect ratings. Mauchly's test indicated that the assumption of sphericity had been violated, $\chi^{2}(2)=13.93, p=0.001$, therefore degrees of freedom were corrected using Huynh-Feldt estimates of sphericity $(\varepsilon=0.920)$. This analysis revealed a significant main effect of time, $F(1.84,169.36)=8.70, \eta_{\mathrm{p}}^{2}=0.077$, $p<0.001$, observed power $=0.99$, a priori power $=1.00$ (assuming $d=0.5$ ); a significant time by group interaction, $F(5.52,169.36)=2.27, \eta_{\mathrm{p}}^{2}=0.069, p=0.044$, observed power $=0.99$, a priori power $=1.00$ (assuming $d=0.5)$; but no main effect of group, $F(3,92)=0.93, \eta^{2}{ }_{\mathrm{p}}=0.029$, $p=0.430$, observed power $=0.34$, a priori power $=1.00$ (assuming $d=0.5$ ). To explore this interaction, we conducted one-way ANOVAs at each time point and found no significant main effect of group (all $p_{\mathrm{s}}>0.238$; observed

Table 5 Means and standard deviations of spider fear, positive affect, and negative affect across group and time

\begin{tabular}{|c|c|c|c|c|c|}
\hline & Ambivalent $(N=16)$ & Engagers $(N=18)$ & Avoiders $(N=22)$ & Indifferent $(N=40)$ & $F$ \\
\hline \multicolumn{6}{|l|}{ Spider fear } \\
\hline T1: Baseline & $62.19(17.50)$ & $50.61(24.42)$ & $59.41(17.43)$ & $48.28(24.50)$ & 2.22 \\
\hline T2: After introduction to spider & $78.31(14.29)$ & $65.33(23.84)$ & $74.73(14.79)$ & $50.43(28.35)$ & $8.31 * * *$ \\
\hline T3: At end of study & $65.06(23.33)$ & $32.06(16.85)$ & $42.68(23.62)$ & $21.23(19.22)$ & $18.41 * * *$ \\
\hline \multicolumn{6}{|l|}{ Positive affect } \\
\hline T1: Baseline & $30.56(6.98)$ & $29.83(6.66)$ & $27.09(6.99)$ & $29.75(7.50)$ & 0.95 \\
\hline T2: After introduction to spider & $28.75(8.93)$ & $29.11(7.16)$ & $25.41(7.81)$ & $29.68(7.98)$ & 1.44 \\
\hline T3: At end of study & $28.63(6.87)$ & $28.11(9.40)$ & $25.45(8.95)$ & $25.00(7.66)$ & 1.14 \\
\hline \multicolumn{6}{|l|}{ Negative affect } \\
\hline T1: Baseline & $21.62(4.11)$ & $19.72(6.07)$ & $20.32(4.43)$ & $18.75(5.11)$ & 1.37 \\
\hline T2: After introduction to spider & $27.69(4.42)$ & $23.78(6.81)$ & $26.36(5.70)$ & $20.67(7.24)$ & $6.25 * * *$ \\
\hline T3: At end of study & $23.56(7.83)$ & $15.28(4.00)$ & $16.55(5.60)$ & $12.88(3.26)$ & $17.89 * * *$ \\
\hline
\end{tabular}

Note: Standard deviations from the mean are presented in brackets. One-way ANOVAs were performed to examine between-group differences. $* * * p<0.001$ 
power $=0.26$ for time $1,0.38$ for time 2 , and 0.31 for time 3 ; a priori power $=0.99$, assuming $d=0.5$ ).

We also conducted the same 3 (time 1 vs. time 2 vs. time 3 ) $\times 4$ (ambivalent vs. engagers vs. avoiders vs. indifferent) mixed ANOVA on negative affect ratings. There was a main effect of time, $F(2,184)=75.08, \eta_{\mathrm{p}}^{2}=0.449$, $p<0.001$, observed power $=1.00$, a priori power $=1.00$ (assuming $d=0.5)$; a main effect of group, $F(3,92)=9.99$, $\eta_{\mathrm{p}}^{2}=0.246, p<0.001$, observed power $=0.99$, a priori power $=1.00$ (assuming $d=0.5$ ); and a time by group interaction, $F(6,184)=4.59, \eta_{\mathrm{p}}^{2}=0.130, p<0.001$, observed power $=1.00$, a priori power $=1.00$ (assuming $d=0.5)$. To better understand this interaction, we conducted one-way ANOVAs at each time point. Results showed a main effect of group on negative affect after initial introduction of the spider, $F(3,92)=6.25, \eta_{\mathrm{p}}^{2}=0.169, p<0.001$, observed power $=0.96$, a priori power $=0.99$ (assuming $d=0.5)$; and at the end of the study, $F(3,92)=17.89, \eta_{\mathrm{p}}^{2}=0.368$, $p<0.001$, observed power $=1.00$, a priori power $=0.99$ (assuming $d=0.5)$; but not at baseline, $F(3,92)=1.37$, $\eta_{\mathrm{p}}^{2}=0.030, p=0.256$, observed power $=0.26$, a priori power $=0.99$ (assuming $d=0.5$ ). Post hoc comparisons (Tukey's HSD) revealed that after initial introduction of the spider, the avoiders and ambivalent groups reported significantly higher negative affect than the indifferent group (both $p_{\mathrm{s}}<0.007$; observed power $=0.89$ for avoiders vs. indifferent, and 0.97 for ambivalent vs. indifferent; a priori power $=0.46$ for avoiders vs. indifferent, and 0.38 for ambivalent vs. indifferent, assuming $d=0.5$ ). At the end of the study, the ambivalent group had greater negative affect than all other groups (all $p_{\mathrm{s}}<0.001$; observed power $=0.69$ for ambivalent vs. engagers, 0.86 for ambivalent vs. avoiders, and 0.99 for ambivalent vs. indifferent; a priori power $=0.29$ for ambivalent vs. engagers, 0.32 for ambivalent vs. avoiders, and 0.38 for ambivalent vs. indifferent, assuming $d=0.5$ ).

Hence, our third hypothesis was confirmed: ambivalent individuals reported higher spider fear and more negative affect at the end of the study than all other motivation groups. While other groups demonstrated habituation to threat over the course of the study (as demonstrated by significant reductions in both spider fear and negative affect), ambivalent individuals did not.

\section{Did Performance on the Metronome Response Task Differ According to Motivation?}

Means and standard deviations of MRT performance measures are presented in Table 6. To examine the impact of motivation on MRT performance, we conducted multiple one-way ANOVAs in which each performance measure was tested as a function of group (i.e., ambivalent vs. engagers vs. avoiders vs. indifferent). We observed a significant main effect of group for mean RRT variance, $F(3,92)=2.92$, $\eta_{\mathrm{p}}^{2}=0.087, p=0.038$, observer power $=0.69$, a priori power $=0.99$ (assuming $d=0.5)$; and for the proportion of spider-related thoughts, $F(3,92)=10.54, \eta_{\mathrm{p}}^{2}=0.256$, $p<0.001$, observed power $=0.99$, a priori power $=0.99$ (assuming $d=0.5$ ). Post hoc comparisons (Tukey's HSD) revealed that the engagers group displayed higher mean RRT variance than the indifferent group, $p=0.041$, observer power $=0.66$, a priori power $=0.41$ (assuming $d=0.5)$, indicating poorer performance throughout the MRT. In addition, the engagers group also reported a higher proportion of spider-related thoughts than the avoiders and indifferent groups (both $p_{\mathrm{s}}<0.001$; observer power $=0.92$ for engager vs. avoiders, and 0.99 for engagers vs. indifferent; a priori power $=0.34$ for engagers vs. avoiders, and 0.41 for engagers vs. indifferent, assuming $d=0.5$ ).

Therefore, only the engagers group demonstrated different performance on the MRT: they had more thoughts about the spider and performed more poorly overall. There was not significant difference in task performance between the ambivalent, avoiders, and indifferent groups.

\section{Discussion}

The purpose of this study was to examine the impact of motivation to look at or to avoid looking at threat on attentional deployment, spider fear, and mood state while individuals complete an attentionally demanding task. Participants varied in their motivation to look at or to avoid looking at the spider. Motivation to look at the spider had very little relationship with motivation to perform well on the current task, indicating that participants held goals that were independent of each other. Consistent with Nelson et al. (2015),
Table 6 Means and standard deviations of MRT performance measures by group

\begin{tabular}{|c|c|c|c|c|c|}
\hline & $\begin{array}{l}\text { Ambivalent } \\
(N=16)\end{array}$ & $\begin{array}{l}\text { Engagers } \\
(N=18)\end{array}$ & $\begin{array}{l}\text { Avoiders } \\
(N=22)\end{array}$ & $\begin{array}{l}\text { Indifferent } \\
(N=40)\end{array}$ & $F$ \\
\hline Mean RRT variance & $7.89(0.40)$ & $8.28(0.52)$ & $7.98(0.36)$ & $7.93(0.49)$ & $2.92 *$ \\
\hline $\begin{array}{l}\text { Proportion of spider- } \\
\text { related thoughts \% }\end{array}$ & $44.79(21.92)$ & $56.48(20.92)$ & $35.26(17.30)$ & $30.00(13.32)$ & $10.54 * * *$ \\
\hline
\end{tabular}

Note: Standard deviations from the mean are presented in brackets; $R R T$ rhythmic response time. One-way ANOVAs were performed to examine between-group differences. $* p<0.05, * * * p<0.001$ 
ratings of motivation to look at the spider and motivation to avoid looking were not correlated. As predicted, some participants had low motivation to both look and to avoid looking (indifferent), some were highly motivated to look (engagers), others were highly motivated to avoid looking (avoiders), and some ( $n=16)$ had equally high motivation to look and to avoid looking (ambivalent).

Traditionally, anxiety has been characterized as a dominance of avoidance motivation over approach motivation regarding threat (e.g., Fowles 1987) and it is often assumed that approach and avoidance motivation should have an inverse relationship (see Chen and Bargh 1999). This is also reflected in research methods such as the approach-avoidance task (Klein et al. 2011; Rinck and Becker 2007), which assumes that participants either approach (by pulling the object towards oneself) or avoid (by pushing the object away from oneself). This conceptual framework implies that anxious individuals are a homogenous population and have to choose one response over another when encountering threat. The current study revealed contradictory findings: motivation to look at the spider was not correlated with motivation to avoid looking at the spider, and spider-fearful individuals could be classified into four different motivation groups. More importantly, different motivation groups demonstrated different visual attention to spider, reported different levels of spider fear and negative affect, and also performed differently on the MRT. If we had treated our sample as a homogenous group and analyzed the data as a whole, we would have missed this significant variance and drawn conclusions that are inaccurate. Moreover, as we observed small to moderate correlations between motivation ratings and various dependent measures (same as in Nelson et al. 2015), we believe it is unlikely that our motivation ratings reflected participants' post-hoc evaluation of their visual attention to threat.

Our second hypothesis was that participants' motivation to look at or to avoid looking at the spider would influence their visual attention to it. Based on Nelson et al. (2015), we hypothesized that the ambivalent group would uniquely exhibit initial facilitated attention to the spider. Instead we found both ambivalent and engagers groups were more likely to have their first fixations on the spider than gift cards. Thus, ambivalent motivation may not be uniquely associated with hypervigilance towards threat. This is consistent with findings from previous studies showing that most spider-fearful individuals presented with facilitated orienting towards spider stimuli (Mogg and Bradley 2006; Ohman et al. 2001; Vrijsen et al. 2009). However, the engagers and ambivalent groups differed on how they maintained their initial attention on threat. While the engagers group had longer first fixations on the spider than gift cards, the ambivalent group showed no such difference. This finding is contradictory to some earlier studies in which spider-fearful individuals demonstrated difficulty in disengaging from threat
(Paulitzki et al. 2008; Wilson et al. 2015). More research is need to confirm if ambivalent individuals can be characterized by initial facilitated orienting to threat but little or no maintenance of initial attention on threat.

As in Nelson et al. (2015), each motivation group showed different viewing patterns over the course of the MRT. When we examined attentional bias to threat across the 10 viewing intervals, we saw that the engagers group consistently exhibited stronger attentional bias to threat, while the avoiders and indifferent group consistently exhibited weaker or no attentional bias to threat. On the contrary, the ambivalent group showed a weak threat bias in the first two intervals, a stronger threat bias in the third and fourth intervals (on par with the engagers group), followed by a weak threat bias in the rest of the intervals. This observation provides support to our hypothesis that different motivation groups would have different patterns of visual attention to threat across time. However, it remains unclear to us why the ambivalent group experienced a sudden increase in their attentional bias to threat. More research is needed to explore if our finding can be replicated, and if so, what may account for this change. Future work may want to look at impact of one gaze on the next, as it was done in I. Amir et al. (2016).

Our findings also suggest that people who are motivated to avoid or monitor a threat are quite able to exert control over their attention. This was further supported by our observation that the engagers group reported more spiderrelated thoughts and performed more poorly on the MRT (as they were supposedly more motivated to pay attention to the spider). However, for those who are experiencing a conflict between both wanting to avoid the treat and wanting to monitor the treat, they would have difficulty deciding on where to deploy their attention (as demonstrated by initial orienting to threat but no maintenance of initial attention on threat, and significant fluctuations in their visual attention to threat over time).

Our third hypothesis was that the ambivalent group would have higher spider fear at the end of the study than other groups, and that they would have a more negative mood state than those in other groups. Both hypotheses were confirmed. It was noteworthy that whereas the engagers, avoiders, and indifferent groups all showed a significant decrease in spider fear and negative affect to below baseline levels, the ambivalent group did not. The indifferent group did not seem to find the spider particularly threatening, showing no significant increase in spider fear after being introduced to the spider. Such findings cannot be attributed to pre-existing differences in spider anxiety, as all four motivation groups scored similarly on the FSQ.

The engagers and avoiders did report greater spider fear after being introduced to it, but their fear seemed to have habituated over the course of the study, and negative affect also declined. However, consistent with Nelson et al. (2015), 
the ambivalent group seemed to experience the most distress. It may be that whereas the engagers mindfully prioritized the goal of threat monitoring over performance, the avoiders prioritized emotion regulation and/or performance. The ambivalent group may have been unable to prioritize and then felt as if they were failing at both monitoring threat and at emotion regulation/performance. These data suggest that the problem in persistent anxiety may not be so much attentional biases to threat, but capacity to resolve conflicting goals. Although the current study demonstrated that ambivalent motivation may be particularly relevant to anxiety, it remains unclear where this motivation derives from. More research is needed to look into factors that may account for ambivalent motivation in some anxious individuals but not others, such as personality traits, threat-related beliefs, and chronicity of anxiety symptoms.

There are several limitations to the current study. The first limitation is the small sample size. As almost half of our participants endorsed an indifferent attitude towards the spider, we had fewer than 20 participants in the ambivalent and engagers group and barely above 20 participants in the avoiders group. This small sample size introduced more variance in our data and contributed to low statistic power as observed in some of our results. We recommend future researchers to recruit more participants and potentially individuals who have been diagnosed with a spider phobia. Similarly, due to the multi-modality design of the current study, we conducted a considerable number of comparisons on various outcome measures (including eye movement indices, subjective ratings, and MRT performance measures) across multiple time intervals (i.e., ten segments of eye movement data), which could lead to inflated Type I error rates (Ranganathan et al. 2016). This is a common issue for eye tracking studies. Although we attempted to ameliorate this problem by only testing a priori hypotheses, limiting the number of analyses, and confirming our findings using a similar and yet different measure (e.g., spider fear vs. negative affect, RRT variance vs. spider-related thoughts, overall bias to threat vs. bias to threat over time), readers should be aware of this limitation when interpreting our results. Another limitation is that we only measured spider fear using subjective reports. We are confident that subjective reports provided reliable measures of spider fear in the present study, as there was a significant correlation between the one-item SUDS and the negative affect subscale of PANAS, and we were able to detect fear activation and habituation using these measures. However, future studies should consider including objective measures of spider fear, such as the behavioural avoidance test (e.g., Van Bockstaele et al. 2011) and startle response to spider stimuli (e.g., Kashdan et al. 2012). Lastly, we lost a considerable amount of data because of the portable eye tracking technology we used in the current study. We were unable to access some of the participants' eye movements in one segment and some of our participants had a low tracking ratio. The current technology also lacked precision, which made it challenging to study early vs. late stage of attention. Future researchers might want to consider using more reliable and precise eye tracking technology.

It should also be noted that our results only pertain to individuals with spider fear. It is possible that individuals without spider fear may behave differently because they do not view the spider as a threat. Nonetheless, more research is needed to confirm this hypothesis. In addition, the current study lacked a true control object for the live spider. We included the basket of gift cards as a reminder to participants that task performance is important (as they would receive an additional reward) and also to create a situation where participants would face competing demands (i.e., attending to task vs. attending to spider), which is more analogous to real-life encounters of threat. Our strategy seemed to have worked as most of our participants reported high motivation to do well on the task. Although we did not intend to use the gift cards as a control object, gift cards and spider were the only two salient stimuli in participants' visual field and almost all participants did look at both stimuli. Hence, we decided to compare eye movement data between them. However, attending to gift cards should not be mistaken for engaging in the current task, as participants might have done so for different reasons. Some might see gift cards as a distraction from the spider, others might use gift cards as a point of focus or an incentive to do well on the task. Our data seemed to support this, as we found no significant correlation between visual attention to gift cards and performance on the MRT.

Another relevant issue is that the gift cards did not control for some of the features that are unique to the spider (e.g., being a moving animal). This raised the question of whether our findings are spider-specific, or as some research has suggested (Lipp et al. 2004), animal-specific. We believe our results are more specific to spider, as we observed small to moderate correlations between motivation ratings towards spider and other outcome variables, and the observed effects are similar to those from Nelson et al. (2015) where they paired a variety of threat images with control images. There may be merits in including a true control object that is neutral and moving (e.g., a non-threatening animal of a similar size) in future studies.

Nonetheless, results from the present study have important implications for treating anxiety in clinical practice. Performing the MRT in close proximity to a live tarantula for $30 \mathrm{~min}$ can be considered as a behavioural exposure for spider-fearful individuals. Almost all participants reported a significant increase in spider fear upon seeing the tarantula, which is consistent with the observation that anxious individuals show fear activation in the beginning of exposure therapy (see Kamphuis and Telch 2000). 
At the end of this exposure, the engagers, avoiders, and indifferent groups all reported a significant decrease in spider fear, which is again consistent with the observation that anxious individuals show fear habituation over the course of exposure therapy (see Kashdan et al. 2012). On the contrary, ambivalent individuals were the only group whose anxiety did not decline in response to exposure. Our findings suggest that ambivalent motivation towards threat may play a critical role in the maintenance of anxiety. This may explain why some anxious individuals do not respond to exposure therapy (see Andersson et al. 2009; Zlomke and Davis 2008), as they may be unable to resolve this approach-avoidance conflict and feel torn in their deployment of attention towards threat. Hence, we recommend clinicians to have a discussion with their clients about motivation to look and to avoid looking prior to conducting exposure therapy, and address clients' predictions about what would happen if they look and what would happen if they avoid looking. The goal is to encourage ambivalent individuals to look more at the threat during exposure, as it predicts better treatment outcome. In addition, clinicians should work with their clients in monitoring motivation towards threat throughout exposure therapy. This can be easily done by asking clients to rate their motivation to look and avoid looking on a Likert scale (as in our study), as they may be less aware of the extent to which they visually approach and avoid threat.

In summary, the present study offered strong support for the idea that people vary in their motivation to attend to vs. avoid attending to threat, that situational factors and goal prioritization may influence motivation, that motivation has a powerful influence on visual attention to threat, and that people exhibit considerable attentional control based on their motivation. The findings suggest that anxiety persistence may have more to do with goal prioritization than innate attentional biases. Future studies of attentional biases to threat should both take motivation into account and study attention across the time course. Ambivalent motivation to threat should also be targeted in exposure therapy.

Funding Funding was provided Social Sciences and Humanities Research Council of Canada (Grant No.1850-500-105-0654-112440-xxxx0000-000).

\section{Compliance with Ethical Standards}

Conflict of interest The authors declare that they have no conflict of interest.

Ethical approval This study involved human participations. This study received ethical clearance from the Office of Research Ethics at the University of Waterloo (\#20426). All procedures performed in studies involving human participants were in accordance with the ethical standards of the institutional research committee and with the 1964 Helsinki declaration and its later amendments or comparable ethical standards. The manuscript does not contain clinical studies or patient data.

Informed consent Informed consent was obtained from all individual participants included in the study.

\section{References}

Amir, I., Zvielli, A., \& Bernstein, A. (2016). (De) coupling of our eyes and our mind's eye: A dynamic process perspective on attentional bias. Emotion, 16(7), 978-986. https://doi.org/10.1037/emo00 00172.

Amir, N., Elias, J., Klumpp, H., \& Przeworski, A. (2003). Attentional bias to threat in social phobia: Facilitated processing of threat or difficulty disengaging attention from threat? Behaviour Research and Therapy, 41(11), 1325-1335. https://doi.org/10.1016/s0005 -7967(03)00039-1.

Andersson, G., Waara, J., Jonsson, U., Malmaeus, F., Carlbring, P., \& Ost, L. G. (2009). Internet-based self-help versus one-session exposure in the treatment of spider phobia: a randomized controlled trial. Cognitive Behaviour Therapy, 38(2), 114-120. https ://doi.org/10.1080/16506070902931326.

Bar-Haim, Y., Lamy, D., Pergamin, L., Bakermans-Kranenburg, M. J., \& van IJzendoorn, M. H. (2007). Threat-related attentional bias in anxious and nonanxious individuals: a meta-analytic study. Psychological Bulletin, 133(1), 1-24. https://doi. org/10.1037/0033-2909.133.1.1.

Bryant, R. A., \& Harvey, A. G. (1995). Processing threatening information in posttraumatic stress disorder. Journal of Abnormal Psychology, 104(3), 537-541.

Buckley, T. C., Blanchard, E. B., \& Hickling, E. J. (2002). Automatic and strategic processing of threat stimuli: A comparison between PTSD, panic disorder, and non-anxiety controls. Cognitive Therapy and Research, 26(1), 97-115.

Chen, M., \& Bargh, J. A. (1999). Consequences of automatic evaluation: Immediate behavioral predispositions to approach or avoid the stimulus. Personality and Social Psychology Bulletin, 25(2), 215-224.

Cisler, J. M., \& Koster, E. H. (2010). Mechanisms of attentional biases towards threat in anxiety disorders: An integrative review. Clinical Psychology Review, 30(2), 203-216. https://doi.org/10.1016/j. cpr.2009.11.003.

Cisler, J. M., \& Olatunji, B. O. (2010). Components of attentional biases in contamination fear: evidence for difficulty in disengagement. Behaviour Research and Therapy, 48(1), 74-78. https://doi. org/10.1016/j.brat.2009.09.003.

Crawford, J. R., \& Henry, J. D. (2004). The positive and negative affect schedule (PANAS): Construct validity, measurement properties and normative data in a large non-clinical sample. British Journal of Clinical Psychology, 43(Pt 3), 245-265.

Derryberry, D., \& Reed, M. A. (2002). Anxiety-related attentional biases and their regulation by attentional control. Journal of Abnormal Psychologuy, 111(2), 225-236.

Dunning, J. P., \& Hajcak, G. (2009). See no evil: directing visual attention within unpleasant images modulates the electrocortical response. Psychophysiology, 46(1), 28-33. https://doi.org/10.11 11/j.1469-8986.2008.00723.x.

Elliot, A. J., \& Thrash, T. M. (2002). Approach-avoidance motivation in personality: approach and avoidance temperaments and goals. Journal of Personality and Social Psychology, 82(5), 804-818. https://doi.org/10.1037/0022-3514.82.5.804.

Faul, F., Erdfelder, E., Lang, A.-G., \& Buchner, A. (2007). G*Power 3: A flexible statistical power analysis program for the social, 
behavioral, and biomedical sciences. Behavior Research Methods, 39(2), 175-191.

Fowles, D. C. (1987). Psychophysiology and psychopathology: A motivational approach. Psychophysiology, 25(4), 373-391.

Fox, E., Russo, R., Bowles, R., \& Dutton, K. (2001). Do threatening stimuli draw or hold visual attention in subclinical anxiety? Journal of Experimental Psychology: General, 130(4), 681-700. https ://doi.org/10.1037/0096-3445.130.4.681.

Gray, J. A., \& McNaughton, N. (2000). The neuropsychology of anxiety: An enquiry into the functions of the septo-hippocampal system (2nd ed.). Oxford: Oxford University Press.

Healey, A., Mansell, W., \& Tai, S. (2019). How does goal conflict, and awareness of goal conflict, relate to distress, dysfunction and the outcomes of exposure in spider fear? https://doi.org/10.13140/ RG.2.2.22398.43843.

Hermans, D., Vansteenwegen, D., \& Eelen, P. (1999). Eye movement registration as a continuous index of attention deployment: Data from a group of a spider anxious students. Cognition and Emotion, 13(4), 419-434.

Johnson, D. R. (2009). Goal-directed attentional deployment to emotional faces and individual differences in emotional regulation. Journal of Research in Personality, 43(1), 8-13. https://doi. org/10.1016/j.jrp.2008.09.006.

Kamphuis, J. H., \& Telch, M. J. (2000). Effects of distraction and guided threat reappraisal on fear reduction during exposure-based treatments for specific fears. Behaviour Research and Therapy, 38(12), 1163-1181. https://doi.org/10.1016/s0005-7967(99)00147 -3 .

Kashdan, T. B., Adams, L., Read, J., \& Hawk, L., Jr. (2012). Can a onehour session of exposure treatment modulate startle response and reduce spider fears? Psychiatry Research, 196(1), 79-82. https:// doi.org/10.1016/j.psychres.2011.12.002.

Kelly, R. E., Mansell, W., \& Wood, A. M. (2015). Goal conflict and well-being: A review and hierarchical model of goal conflict, ambivalence, self-discrepancy and self-concordance. Personality and Individual Differences, 85, 212-229. https://doi.org/10.1016/j. paid.2015.05.011.

Klein, A. M., Becker, E. S., \& Rinck, M. (2011). Approach and avoidance tendencies in spider fearful children: the approach-avoidance task. Journal of Child and Family Studies, 20(2), 224-231. https ://doi.org/10.1007/s10826-010-9402-7.

Koster, E. H., Crombez, G., Verschuere, B., Van Damme, S., \& Wiersema, J. R. (2006). Components of attentional bias to threat in high trait anxiety: Facilitated engagement, impaired disengagement, and attentional avoidance. Behaviour Research and Therapy, 44(12), 1757-1771. https://doi.org/10.1016/j. brat.2005.12.011.

Lipp, O. V., Derakshan, N., Waters, A. M., \& Logies, S. (2004). Snakes and cats in the flower bed: Fast detection is not specific to pictures of fear-relevant animals. Emotion, 4(3), 233-250. https://doi. org/10.1037/1528-3542.4.3.233.

Mathews, A., \& Mackintosh, B. (1998). Cognitive model of selective processing in anxiety. Cognitive Therapy and Research, 22(6), 539-560. https://doi.org/10.1023/A:1018738019346.

Mogg, K., \& Bradley, B. P. (1998). A cognitive-motivational analysis of anxiety. Behaviour Research and Therapy, 36(9), 809-848.

Mogg, K., \& Bradley, B. P. (2005). Attentional bias in generalized anxiety disorder versus depressive disorder. Cognitive Therapy and Research, 29(1), 29-45. https://doi.org/10.1007/s 1060 8-005-1646-y.

Mogg, K., \& Bradley, B. P. (2006). Time course of attentional bias for fear-relevant pictures in spider-fearful individuals. Behaviour Research and Therapy, 44(9), 1241-1250. https://doi. org/10.1016/j.brat.2006.05.003.

Mogg, K., Bradley, B. P., Miles, F., \& Dixon, R. (2004). Time course of attentional bias for threat scenes: Testing the vigilance-avoidance hypothesis. Cognition \& Emotion, 18(5), 689-700. https://doi.org/10.1080/02699930341000158.

Muris, P., \& Merckelbach, H. (1996). A comparison of two spider fear questionnaires. Journal of Behavior Therapy and Experimental Psychiatry, 27(3), 241-244.

Nelson, A. L., Purdon, C., Quigley, L., Carriere, J., \& Smilek, D. (2015). Distinguishing the roles of trait and state anxiety on the nature of anxiety-related attentional biases to threat using a free viewing eye movement paradigm. Cognition Emotion, 29(3), 504-526. https://doi.org/10.1080/02699931.2014.922460.

Ohman, A., Flykt, A., \& Esteves, F. (2001). Emotion drives attention: Detecting the snake in the grass. Journal of Experimental Psychology. General, 130(3), 466-478. https://doi.org/10.1037/ AXJ96-3445.130.3.466.

Paulitzki, J. R., Risko, E. F., Oakman, J. M., \& Stolz, J. A. (2008). Doing the unpleasant: How the emotional nature of a threatrelevant task affects task-switching. Personality and Individual Differences, 45(5), 350-355. https://doi.org/10.1016/j. paid.2008.05.003.

Pittig, A., Brand, M., Pawlikowski, M., \& Alpers, G. W. (2014). The cost of fear: Avoidant decision making in a spider gambling task. Journal of Anxiety Disorders, 28(3), 326-334. https://doi. org/10.1016/j.janxdis.2014.03.001.

Psychology Software Tools, I. (2007). E-prime 2.0 professional. Pittsburgh: Psychology Software Tools, Inc.

Rachman, S. (2004). Anxiety (2nd ed.). Hove: Psychology Press.

Ranganathan, P., Pramesh, C. S., \& Buyse, M. (2016). Common pitfalls in statistical analysis: The perils of multiple testing. Perspectives in Clinical Research, 7(2), 106-107. https://doi. org/10.4103/2229-3485.179436.

Richeson, J. A., \& Trawalter, S. (2008). The threat of appearing prejudiced and race-based attentional biases. Psychological Science, 19(2), 98-102. https://doi.org/10.1111/j.1467-9280.2008.02052 .x.

Rinck, M., \& Becker, E. S. (2006). Spider fearful individuals attend to threat, then quickly avoid it: Evidence from eye movements. Journal of Abnormal Psychology, 115(2), 231-238. https://doi. org/10.1037/0021-843X.115.2.231.

Rinck, M., \& Becker, E. S. (2007). Approach and avoidance in fear of spiders. Journal of Behavior Therapy and Experimental Psychiatry, 38(2), 105-120. https://doi.org/10.1016/j.jbtep.2006.10.001.

Rinck, M., Becker, E. S., Kellermann, J., \& Roth, W. T. (2003). Selective attention in anxiety: Distraction and enhancement in visual search. Depression and Anxiety, 18(1), 18-28. https://doi. org/10.1002/da.10105.

Rinck, M., Reinecke, A., Ellwart, T., Heuer, K., \& Becker, E. S. (2005). Speeded detection and increased distraction in fear of spiders: Evidence from eye movements. Journal of Abnormal Psychology, 114(2), 235-248. https://doi.org/10.1037/0021-843X.114.2.235.

Seli, P., Carriere, J. S., \& Smilek, D. (2015a). Not all mind wandering is created equal: Dissociating deliberate from spontaneous mind wandering. Psychological Research, 79(5), 750-758. https://doi. org/10.1007/s00426-014-0617-x.

Seli, P., Cheyne, J. A., \& Smilek, D. (2013). Wandering minds and wavering rhythms: Linking mind wandering and behavioral variability. Journal of Experimental Psychology: Human Perception and Performance, 39(1), 1-5. https://doi.org/10.1037/a0030954.

Seli, P., Cheyne, J. A., Xu, M., Purdon, C., \& Smilek, D. (2015b). Motivation, intentionality, and mind wandering: Implications for assessments of task-unrelated thought. Journal of Experimental Psychology. Learning, Memory, and Cognition, 41(5), 14171425. https://doi.org/10.1037/xlm0000116.

SensoMotoric Instruments Inc. (2009). iView X system manual. Teltow, Germany: SensoMotoric Instruments, Inc.

SensoMotoric Instruments Inc. (2014). BeGaze manual. Teltow, Germany: SensoMotoric Instruments, Inc. 
Siegel, P., \& Warren, R. (2013). The effect of very brief exposure on experienced fear after in vivo exposure. Cognition Emotion, 27(6), 1013-1022. https://doi.org/10.1080/02699931.2012.756803.

Szymanski, J., \& O’Donohue, W. (1995). Fear of spiders questionnaire. Journal of Behavior Therapy and Experimental Psychiatry, 26(1), 31-34. https://doi.org/10.1016/0005-7916(94)00072-T.

Teachman, B. A., \& Woody, S. R. (2003). Automatic processing in spider phobia: Implicit fear associations over the course of treatment. Journal of Abnormal Psychology, 112(1), 100-109. https ://doi.org/10.1037/0021-843x.112.1.100.

Van Bockstaele, B., Verschuere, B., Koster, E. H., Tibboel, H., De Houwer, J., \& Crombez, G. (2011). Effects of attention training on self-reported, implicit, physiological and behavioural measures of spider fear. Journal of Behavior Therapy and Experimental Psychiatry, 42(2), 211-218. https://doi.org/10.1016/j.jbtep 2010.12.004.

Vrijsen, J. N., Fleurkens, P., Nieuwboer, W., \& Rinck, M. (2009). Attentional bias to moving spiders in spider fearful individuals. Journal of Anxiety Disorders, 23(4), 541-545. https://doi. org/10.1016/j.janxdis.2008.11.002.

Watson, D., Clark, L. A., \& Tellegen, A. (1988). Development and validation of brief measures of positive and negative affect: The PANAS Scales. Journal of Personality and Social Psychology, 54(6), 1063-1070.
Williams, J. M., Watts, F. N., MacLeod, C., \& Mathews, A. (1988). Cognitive psychology and emotional disorders. Chichester, England: Wiley.

Wilson, K. M., Russell, P. N., \& Helton, W. S. (2015). Spider stimuli improve response inhibition. Consciousness and Cognition, 33, 406-413. https://doi.org/10.1016/j.concog.2015.02.014.

Xu, M., Purdon, C., Seli, P., \& Smilek, D. (2017). Mindfulness and mind wandering: The protective effects of brief meditation in anxious individuals. Consciousness and Cognition, 51, 157-165. https://doi.org/10.1016/j.concog.2017.03.009.

Yiend, J., \& Mathews, A. (2001). Anxiety and attention to threatening pictures. The Quarterly Journal of Experimental Psychology A, 54(3), 665-681. https://doi.org/10.1080/713755991.

Zlomke, K., \& Davis, T. E., 3rd. (2008). One-session treatment of specific phobias: A detailed description and review of treatment efficacy. Behavior Therapy, 39(3), 207-223. https://doi.org/10.1016/j. beth.2007.07.003.

Publisher's Note Springer Nature remains neutral with regard to jurisdictional claims in published maps and institutional affiliations. 